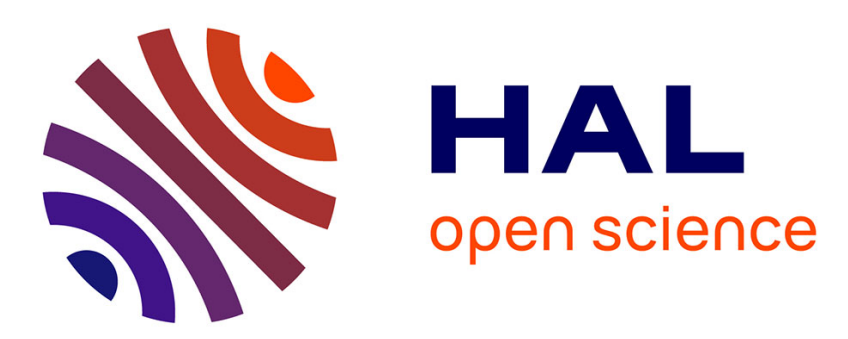

\title{
Motivation for Learning: Adaptive Gamification for Web-based Learning Environments
}

\author{
Baptiste Monterrat, Elise Lavoué, Sébastien George
}

\section{To cite this version:}

Baptiste Monterrat, Elise Lavoué, Sébastien George. Motivation for Learning: Adaptive Gamification for Web-based Learning Environments. 6th International Conference on Computer Supported Education (CSEDU 2014), Apr 2014, Barcelona, Spain. pp.117-125. hal-01130791

\section{HAL Id: hal-01130791 https://hal.science/hal-01130791}

Submitted on 12 Mar 2015

HAL is a multi-disciplinary open access archive for the deposit and dissemination of scientific research documents, whether they are published or not. The documents may come from teaching and research institutions in France or abroad, or from public or private research centers.
L'archive ouverte pluridisciplinaire $\mathbf{H A L}$, est destinée au dépôt et à la diffusion de documents scientifiques de niveau recherche, publiés ou non, émanant des établissements d'enseignement et de recherche français ou étrangers, des laboratoires publics ou privés. 


\title{
Motivation for Learning: Adaptive Gamification for Web-based Learning Environments
}

\author{
Baptiste Monterrat ${ }^{1}$, Élise Lavoué ${ }^{2}$, Sébastien George ${ }^{3}$ \\ ${ }^{1}$ Université de Lyon, CNRS, INSA-Lyon, LIRIS, UMR5205, F-69621, France \\ ${ }^{2}$ Magellan, IAE Lyon, Université Jean Moulin Lyon 3, France \\ ${ }^{3}$ LUNAM Université, Université du Maine, EA 4023, LIUM, 72085 Le Mans, France \\ baptiste.monterrat@insa-lyon.fr,elise.lavoue@univ-lyon3.fr,sebastien.george@univ-lemans.fr
}

Keywords: Gamification, Adaptation, Learning Environment, Motivation, User Model

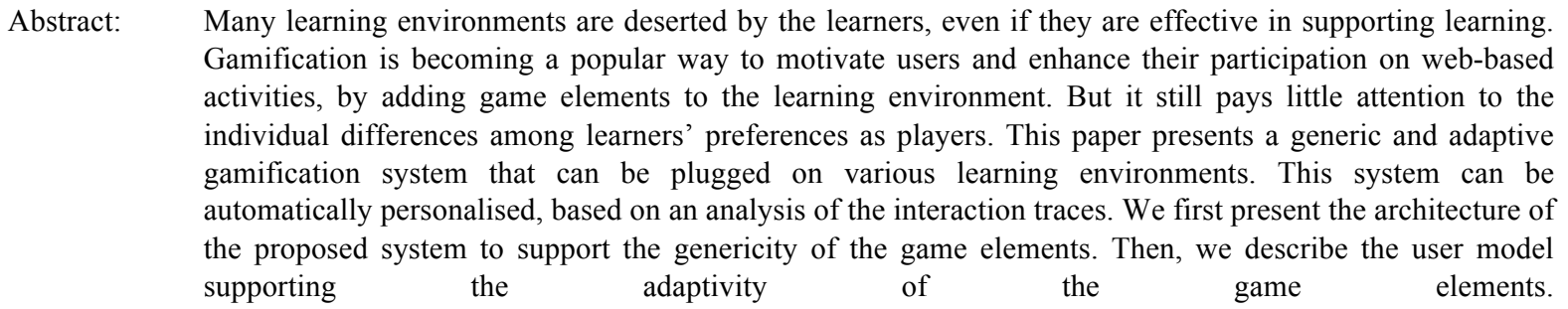

\section{INTRODUCTION TO GAMIFICATION IN LEARNING}

Many learning environments have been shown to be effective when used, but are quickly deserted by most of the learners because of a lack of motivation. Gamification is becoming a popular way to motivate user participation on web based activities. "When done well, gamification helps align our interests with the intrinsic motivation of our players" (Zichermann et al., 2011). Although this concept is not new (Deterding et al., 2011), yet little research treats its uses in learning contexts. This paper proposes a generic and personalised gamification system to raise motivation in learning environments that are not intrinsically motivating.

\subsection{The Need for Genericity}

Turning a learning environment into a game is a complex process. Currently, if the designers of a learning environment are interested in gamifying it, they have to re-design and re-implement the game elements especially for this environment. This could be very complex and require a lot of time, whereas the elements will not be reusable. The existence of generic game elements would address this problem.

Achievements systems like Mozilla OpenBadges (Mozilla 2011) address this need for genericity, but using badges only is a poor way to gamify. Maciuszek (2010) used a component-based framework for implementing educational games. It allows turning a learning software into a learning game by changing only the user interface components. However, the initial software needs to be already compatible with this framework in order to be turned into a game, which is not the case with most existing learning environments.

Thus, we aim to develop gamification as an independent layer that could be plugged on learning environments without changing them.

\subsection{The Need for Adaptivity}

When trying to motivate with games, an important difficulty comes from the fact that people do not have the same expectations, and do not have the same emotional responses to game mechanics (Yee, 2006). A common approach to fulfil these expectations is to add gamification features for all the player types within the application, but there is a 
high risk of overloading the user interface. That is why gamification needs to be personalized. Various researches contributed to the field of adaptive games, by adapting the user interface, the level of difficulty (Andrade, 2006), the pedagogical scenario (Marne, 2013), or the feedback (Conati et al., 2009). We aim at developing an adaptive motivational system addressing the three deficiencies highlighted below.

The first lack identified in existing works is about games genre and dynamics. Game dynamics are defined by Zicherman et al. (2011) as "the player's interactions with the game mechanics". Related works in adaptive games share the goal of increasing the game's acceptance and usability, but the game dynamics remains the same.

The second lack concerns the adaptation of gamification. While many works focus on the adaptation of games, few are interested in the adaptation of gamification. Ferro et al. (2013) are among the first researchers to conduct works on personalised gamification. They are trying to relate directly game mechanics and game elements to both player types and personality types.

The third lack concerns research on adaptation of multi-player games. It has been shown in the game adaptation techniques review of Hocine et al. (2011). As gamification mainly relies on competitive and social features, it is important to consider ways to apply it for groups of users.

\subsection{Main Research Questions}

Our research works aim at developing a motivating system, adaptive and adaptable to various web-based learning activities.

The main research questions related to this goal are: (1) How to characterise the game elements to make them generic and pluggable to the learning environment? (2) Which user model can handle the adaptivity of the game elements? (3) Which architecture can support the tracking, the adaption, and the integration of the game elements?

Section 2 is dedicated to the state of the art related to gamification and game elements. Then in section 3 we present the overall architecture of the system to make gamification generic. In section 4 we provide details about our user model to make gamification adaptive. We finally conclude about the contribution of the paper and present future works in sections 5 and 6.

\section{STATE OF THE ART}

\subsection{Serious Game or Gamification}

Games and fun have proven to enhance motivation in learning activities. But various approaches are used to add fun in different cases. The most popular ones are learning games and gamification. Learning games refer to the use of digital games for learning purposes (Prensky, 2001). Gamification has been defined more recently as "the use of game design elements in non-gaming contexts" (Deterding et al., 2011). These two approaches are often poorly distinguished one from the other. However, they differ by their design process and by the resulting application (see Table 1).

Table 1: Differences between a learning game and a gamified application.

\begin{tabular}{|l|l|l|}
\hline & Learning game & $\begin{array}{l}\text { Gamified } \\
\text { application }\end{array}$ \\
\hline $\begin{array}{l}\text { Design } \\
\text { process }\end{array}$ & $\begin{array}{l}\text { Designed as a } \\
\text { game from the } \\
\text { beginning }\end{array}$ & $\begin{array}{l}\text { Adding game } \\
\text { mechanics to an } \\
\text { existing application }\end{array}$ \\
\hline $\begin{array}{l}\text { Resulting } \\
\text { application }\end{array}$ & $\begin{array}{l}\text { A game with } \\
\text { educational } \\
\text { elements }\end{array}$ & $\begin{array}{l}\text { A learning } \\
\text { application enriched } \\
\text { by game mechanics }\end{array}$ \\
\hline
\end{tabular}

In this work, we focus on gamification. On the one hand, it can be based on existing learning environments. On the other hand, with gamification the game elements are not central but peripheral, which fosters their adaptivity. Thus gamification can become a "fun layer" that could be plugged on several applications (Blind, 2013).

\subsection{User Model and Adaptation}

\subsubsection{Distinguishing Learner and Player}

In the game-based learning field, user adaptation can focus on the user as a learner, or as a player, because each user is both of them. Research on learner model focus on the relation between the learner and the knowledge. For example, the theory of adaptive hypermedia (Brusilovsky, 2001) tends to adapt the content of the user's learning activity.

In our work, the role of user modelling is to adapt the game elements of the gamification layer. Accordingly, we assume that the learner part of the user model is handled by the existing learning application core that manages the learning activity, while the gamification system focuses on the player 
part. That is why we are particularly interested in player model in next part.

\subsubsection{Player Models}

Many studies have been conducted about why people play games. For example, Bartle (1996) identifies four player types: killer, achiever, socialiser, and explorer. Yee (2006) identifies three main motivation components: achievement, social and immersion. Lazzaro (2004) observes four motivational factors for playing games: hard fun, easy fun, altered state and people factor. Moreover, with the growing interest for gamification since a few years, various companies and game designers propose their own types of gamers (Kotaku, 2012, Gamification Co, 2013). In this work, we rely on the classification of Ferro et al. (2013): dominant, objectivist, humanist, inquisitive, and creative. Although it is still a work in progress, this classification has the advantage to relate the player types directly to game mechanics and game elements. This link allow us to personalise and adapt our system to the players (see section 4.2).

\subsubsection{Adaptation Techniques}

Many different adaptation techniques can be found in the state of the art. They are based on various AI methods, as for instance : reinforcement learning to build intelligent adaptive agents (Andrade, 2006), Case-Based Reasoning (CBR), Bayesian network to build a student model (Conati et al., 2009), and evolutionary algorithm to design the tracks of a car racing game (Togelius et al, 2007). This kind of algorithm could be useful to build more accurate user models. In this work, we chose to use adaptation rules written by humans in the first place.

\subsection{Data for Game Adaptation}

According to Kobsa (1999), we distinguish three forms of adaptation: to user data, to usage data and to environment data. All these parameter are important for the game elements personalisation.

\subsubsection{User Data}

We should pay attention to basic data about users, like their age and gender, as it has an influence on their levels of attention and motivation. Charlier et al. (2012) focused on the influence of the player's age. They argue that older adults need games without pressing time constraints. There are also gender differences in motivations for playing games.
For example, Eglesz et al. (2005) found that women prefer Role Playing Games (RPG) while men prefer action, adventure simulation and sport games.

\subsubsection{Usage Data}

Most works presented in the review of Hocine et al. (2011) base their adaptation mainly on the data from user's interactions with the system. It is not a surprise, as this data is generally available without asking questions to the user. These interactions are the basic information used to fill the user model, which may contain the users' emotional state (Poel et al., 2004), their way of learning (Bernardini et al., 2010), their level of success (Andrade et al., 2006), their level of satisfaction, attention, and engagement. As increasing engagement is our goal in this work, it is also a variable we need to track.

The methods for measuring engagement can be based on humans (De Vicente et al., 2002) (observation or self-report), hardware (e.g. eye tracking) or software. The last one is the only one that we can automate in web based applications. (Bouvier et al., 2013) defines a typology of engaged behaviours, to determine if a player is engaged or not, but the interactions tracked are specific to games. Mattheiss et al., (2010) present a list of specific actions that can predict engagement or disengagement in educational computer games. For example, if the learner asks immediately for help without even reading the question, s/he probably does not want to spend much effort. Cocea (2006) also proposed useful examples of behaviors predicting user disengagement, but her approach is qualitative. In this work, we rely particularly on the quantitative and computable method proposed by Beck (2005), called engagement tracing.

\subsubsection{Environment Data}

Kobsa distinguishes the software environment (e.g. the browser), the hardware environment (e.g. the device), and the information about the place (e.g location and objects in the immediate environment). It is generally harder to get information from the third category, but recent technologies like mobile devices localization can help.

In this work, we are interested in knowing the human context, because people do not play the same way if they are alone, with friends, or colleges. For example, (Cheng et al., 2011) tried to find the good moments to play at work, while some works focus on the uses of games in the classroom (Sanchez, 2011). 
It is also important for us to know the device used and the learning context, as some ways of gamifying can be relevant only in some cases.

\section{ARCHITECTURE FOR GENERIC GAMIFICATION}

In this part, we explain how we design game elements to be generic, adaptable, and pluggable on already existing learning environments.

\subsection{Game Elements as Epiphytes}

In order to personalise the fun features, the learning application needs to be able to work with or without these features. That is why we propose to use epiphytic functionalities: applications that are plugged in another application without being necessary. Giroux et al. (1995) define epiphytic systems as follows: (1) the epiphytic system cannot exist without a host, (2) the host can exist without the epiphyte, (3) the host and the epiphyte have independent existences, and (4) the epiphyte does not affect its host.

By implementing the fun functionalities like epiphytes, we can enable or disable them independently for each user, in order to adapt his/her interface without affecting the learning application. This is also a way to foster genericity. We provide below examples of such functionalities that can be activated:

- A leader board of fast learners for competitive users.

- Badges and cups for challenge.

- Ability to leave tips to other users.

- Ability to share scores and success on social networks.

- A chat feature for users interested in socializing.
As shown on Figure 1, the epiphytes (E1 and E2) are distributed in the user interface, but controlled only by the gamification layer, independently from the control of the pedagogical activity.

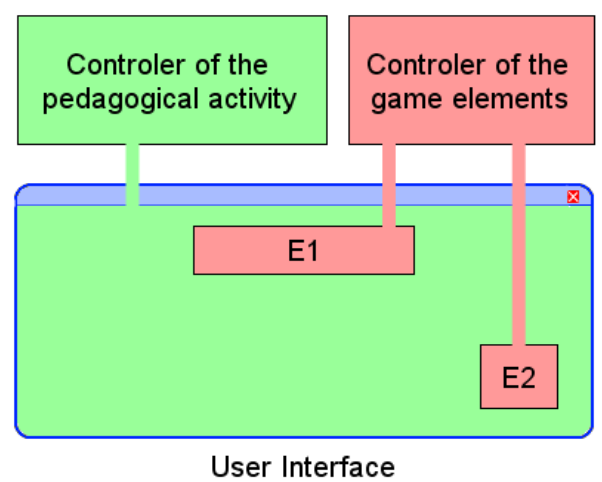

Figure 1: Independence of pedagogical control and game control.

\subsection{Architecture}

An overview of the proposed architecture is presented in Figure 2, which shows the way the gamification system can be plugged in an existing learning environment.

The interactions between the user and the environment are permanently traced (1) and stored in the database. Secondly, the data collected is used by the trace analysis system (2), which calculates frequently the engagement level of the user and stores it in the same base. When the trace analysis system detects user disengagement, it sends an alert to the adaptation engine before the user leaves. When the adaptation engine (3) receives an alert about the low engagement level, it updates the information of the player model in the same base, according to the history of engagement level and the use of activated epiphytes (see section 4.2.2), and selects the epiphytic functionality which best fits the

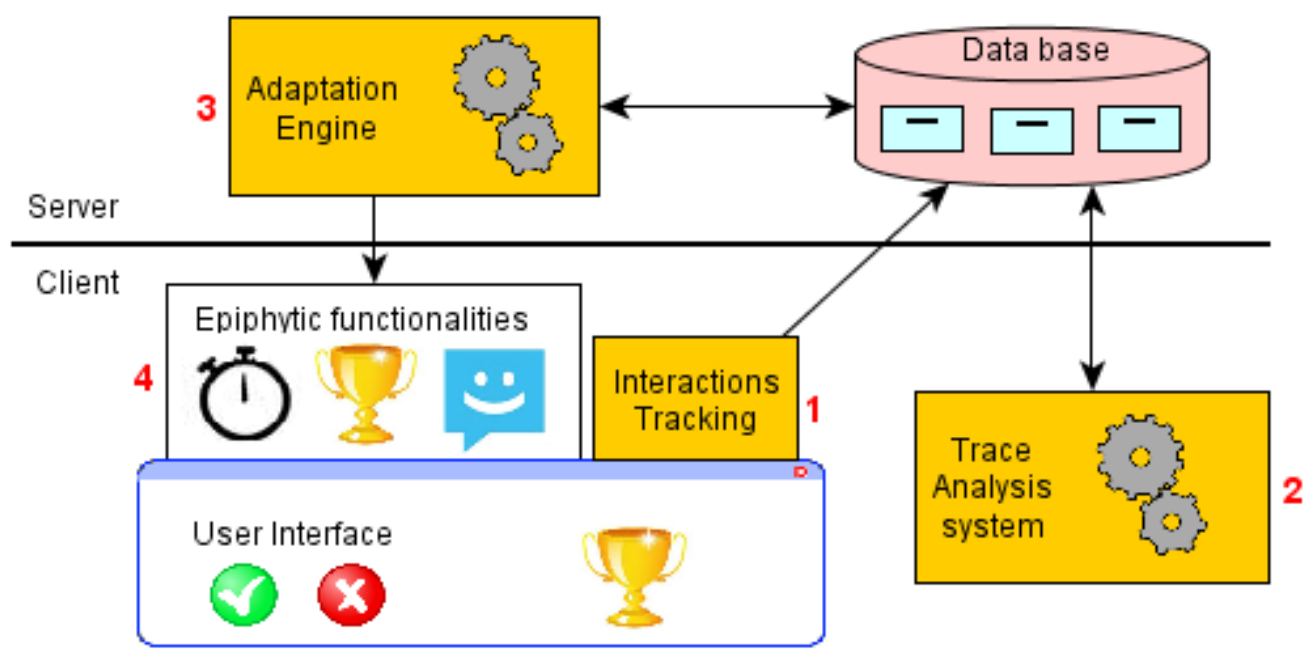

Figure 2: Architecture of the gamification system. 
user's needs. Finally, the selected functionality (4) is introduced in the learning environment (see section 3.3).

\subsection{Integration of the Epiphytic Functionalities}

There are different possible ways of introducing and integrating the functionalities.

On the one hand, the user needs to be aware of the introduction of a new functionality, so we have to inform him/her. On the other hand, the information must not interrupt the learning activity ("the epiphyte does not affect its host"), so a popup window is also not a good solution. As shown on Figure 3, we propose a small tooltip to inform the user without requiring any interaction.

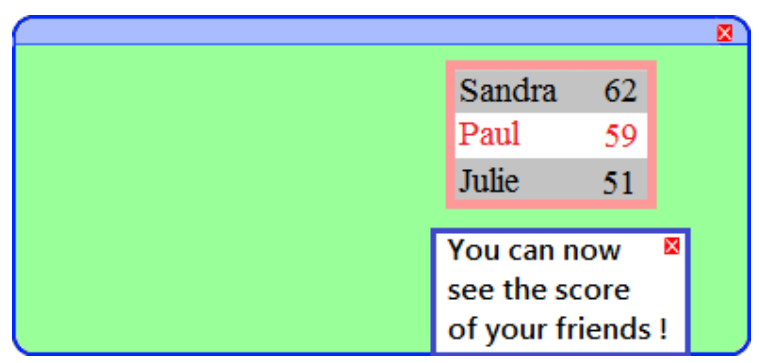

Figure 3: Tooltip to inform the user of changes.

The web technologies allow us to integrate the epiphytes in various ways on the web pages, like panels for the information displayed permanently, and tooltips for epiphytes based on punctual feedback. Examples are shown on Figure 4.

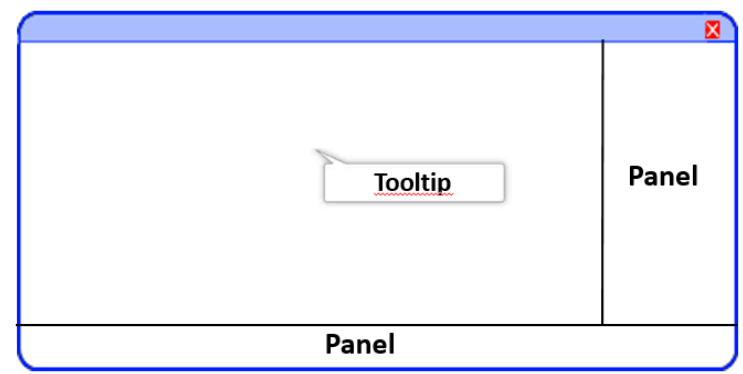

Figure 4: Examples of ways to integrate the epiphytic functionalities in a web user interface.

Finally, it is important to allow the users to disable the activated functionalities. The first reason is that some people do not want to play, and they should not be forced to, as games are a voluntary activity. The second reason is that the adaptation engine may be wrong during the first uses of the environment, and may propose a functionality that does not feet the player's preferences. Thus, the player can close the functionality. By the way this provides a useful feedback to the system about what the user does not like.

\section{MODELS FOR ADAPTATION OF GAMIFICATION}

In section 3.2, we presented the architecture of the system that supports a generic gamification. In this part, we focus on the adaptation process and the player model necessary for this adaptation.

\subsection{User Model}

An overview of the user model is shown on Figure 5 , and its parts are details in the following

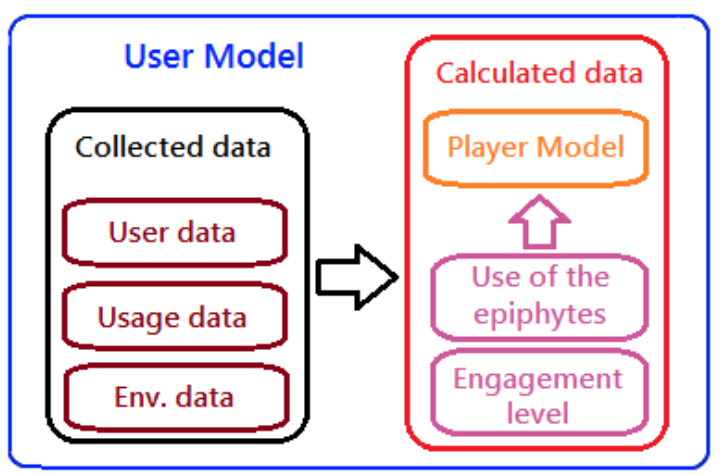

Figure 5: Examples of ways to integrate the epiphytic functionalities in a web user interface. subsections.

The data we want to know is registered within the player model (section 4.2), which tells us which game elements the user may like. It is calculated based on the engagement level, and the use of the epiphytes. The collected data is detailed in section 4.3)

\subsection{Player Model for Adaptive Gamification}

In section 2.2 we explained why we chose to base our model on the classification of Ferro et al. (2013). The list of its motivational factors is presented in Table 2. 
Table 2: Player classification of Ferro.

\begin{tabular}{|c|c|}
\hline Classification & Examples of game elements \\
\hline Dominant & Characters, conflicts \\
\hline Objectivist & Objectives, challenge \\
\hline Humanist & Story/Narrative, dramatic art \\
\hline Inquisitive & Aesthetics, boundaries \\
\hline Creative & Resources, world building \\
\hline
\end{tabular}

When a new user registers on the learning environment, the values of each motivational factor are initialised for him/her according to user data (see section 4.2.2). During the use of the learning environment, the values will change according to the user's interactions (see section 4.2.2).

In addition, each epiphytic functionality also has a list of values associated with the motivational factors. Table 3 provides an example of such association.

Table 3: Example of values associating the epiphyte "leader board" to the motivational factors.

\begin{tabular}{|c|c|}
\hline \multicolumn{2}{|c|}{ Leader board } \\
\hline Dominant & $100 \%$ \\
\hline Objectivist & $40 \%$ \\
\hline Humanist & $20 \%$ \\
\hline Inquisitive & $0 \%$ \\
\hline Creative & $0 \%$ \\
\hline
\end{tabular}

These values are necessary to choose the adequate functionality when we know the user's player profile.

\subsection{Data for Gamification Adaptation}

The three types of data we use for adaptation (Kobsa, 1999) are based on the state of the art presented in part 2.3.

\subsubsection{User Data}

The user data we use for adaptation are

- Birth date

- Gender

These data are static, but they have an influence on the initial values of the player model. Adaptation rules can be extracted from our knowledge on the influence of these data, and these adaptation rules can be used to set better values for the player model of new users (see Table 4 for examples).
Table 4: Examples of adaptation to user data

\begin{tabular}{c|c|}
\hline Tom is a man. When he & Nadia is 62 years old. \\
registers on the learning & When she registers on the \\
environment, his value & learning environment, we \\
for the motivational & set a limit of 2 epiphytes \\
factor "competition" is & activated at the same time. \\
set at $60 \%$, instead of & \\
$40 \%$ for a woman & \\
\hline
\end{tabular}

\subsubsection{Usage Data}

We need to track the user's interactions with both the gamification layer and the learning environment, to evaluate the level of engagement.

Concerning the tracking of the epiphytic functionalities, we can assume that the more a functionality is used, the more the player is sensitive to the motivational factor associated with this functionality.

Table 5: Examples of adaptation to the use of epiphytes

\begin{tabular}{|c|c|}
\hline $\begin{array}{c}\text { Tom is now able to } \\
\text { publish on a social } \\
\text { network when he finished } \\
\text { a learning session. He } \\
\text { uses this functionality } \\
\text { activity on social networks } \\
\text { has been introduced in } \\
\text { Nadia's interface. She } \\
\text { turned it off after one } \\
\text { his value for the } \\
\text { motivational factor } \\
\text { "social" increases. }\end{array}$ & $\begin{array}{c}\text { value for the motivational } \\
\text { factor "social" decreases. }\end{array}$ \\
\hline
\end{tabular}

As some functionalities do not require direct interactions, the system has to find a correlation between the activation of the functionalities and the engagement of the learner. A functionality is effective if it is correlated with a high engagement.

Table 6: Examples of adaptation to the engagement level

\begin{tabular}{|c|c|}
\hline $\begin{array}{l}\text { environment, bu } \\
\text { difference was obs } \\
\text { in his behaviour. } \\
\text { value for the motiv } \\
\text { factor "competit } \\
\text { decreases. }\end{array}$ & $\begin{array}{l}\text { Since the leader board was } \\
\text { added in Nadia's } \\
\text { environment, she is } \\
\text { connected more often and } \\
\text { makes more exercises to } \\
\text { raise her score. Her value } \\
\text { for the motivational factor } \\
\text { "competition" increases. }\end{array}$ \\
\hline
\end{tabular}

Our way of calculating engagement and disengagement is detailed in section 4.4. 


\subsubsection{Environment Data}

In addition, some contextual information are crucial for the gamification engine. Firstly, it is useful to know if the learner is at school, at work, or on free time, as this context has an influence about how people learn.

We are also interested in the device used by the player. In the cloud computing domain, various learning environments are available on mobile devices as on computers, but all features are not necessary relevant or available on any device (e.g. because of the screen size).

Table 7: Examples of adaptation to environment data

\begin{tabular}{|c|c|}
\hline Tom learns at school in & Nadia, whose motivational \\
the computer room with & factor "competition" is \\
his other classmates. & high, sometimes learns on \\
Accordingly, a chat & her smartphone. \\
feature would be useless & Accordingly, we can \\
because he speaks & propose her to compete \\
directly with them. & with players locally near \\
& from her. \\
\hline
\end{tabular}

Summary of the environment data for adaptation:

- Device used.

- Learning context (school, work or personal).

- $\quad$ Size of the group (if school or work).

\subsection{Engagement Tracking}

We have access to one information directly indicating engagement:

- The session dates.

A user connected more often and longer can be considered as more engaged in the activity than another. However, this allows us to know the general engagement but not to compare the engagement level at two distinct times. That's why we need another way to track real time engagement. We use two metrics:

- Too short time to read texts and to answer questions, based on engagement tracing (Beck, 2005).

- Too long time to read or answer questions.

\subsection{Adaptation Technique}

The gamification engine has two roles: updating the player model and selecting a functionality adapted for the user.

To update the player model, a simple algorithm based on adaptation rules increases or decreases the values of the motivational factors, according to the observed use of the epiphytes and the engagement level (see section 4.3.2). Then, the engine has to select the motivational factor with the highest value, and to identify an epiphyte corresponding to this motivational factor, according to the association table (see Table 3). This behaviour must be balanced with some random selections. Selecting the functionality totally randomly would be ignoring the user model. But if there is no random, the functionalities implementing new motivational factors for this user will never be tried.

Finally, as the epiphytes may induce interactions between users, this engine has to "take in account the collaborative aspect and heterogeneity between players, while maintaining the overall coherence of the game" (Hocine et al., 2011). That is why the adaptation engine checks if several users of the group are interested in competing before activating multi-player functionalities.

\section{CONCLUSION AND DISCUSSION}

In this paper, we proposed the architecture of a system to motivate learners by integrating game elements in existing web-based learning environments. This system is both generic and adaptive.

The genericity is based on the use of game elements as epiphytic functionalities, which does not affect the host environment when integrated in the user interface.

The adaptivity is based on a player model that defines the player type matching best with the user. The adaptation process has four steps:

1. Tracing data from the learning environment and the game elements.

2. Evaluating the engagement level of the user.

3. Updating the player model, based on adaptation rules, using basic data about the user, data from the use of the environment, and data describing the learning context.

4. Integrating within the user interface the epiphyte matching best with the player model.

This system is not designed with the goal to turn every learning activity into a game, because games need to be played voluntary and people in some contexts are already motivated to learn. Adaptive gamification should be used with non-intrinsically motivating activities, like memorizing vocabulary or mathematical rules. 
Despite this system has not been tested yet, it addresses three lacks in the literature and existing software:

- It proposes the adaptation of game dynamics, whereas existing systems (e.g Khan Academy, 2006) adapt the learning path and difficulty level.

- It deals with adaptation of gamification, whereas the literature deals more with adaptation of games.

- It proposes the adaptation of multiplayer features, whereas existing environments propose the same game elements for all the users.

\section{FUTURE WORK}

We plan various evaluations and improvements for the system.

Regarding the evaluations, we are currently implementing the system, which will be plugged on "Projet Voltaire", a web-based environment to learn French spelling. For the next step, we will to plug the gamification system on other learning environments, in order to evaluate its genericity.

An experiment will allow us to evaluate the system described in this paper. For instance, we plan to compare the automatic adaptation with the "home made" adaptation: what happens if the user can choose the new functionalities by himself?

Furthermore, some improvements will concern the flexibility of the player model. Sometimes, the player type is not enough to model the user's needs, as they can change during the day. As an example, two motivational factors of Lazzaro (2004) are detailed bellow:

- Hard fun (Players look for challenge, strategy and problem solving).

- Easy fun (Players enjoy intrigue and curiosity).

Whether we expect to relax (easy fun) or to be challenged (hard fun) depends more on our mood than our personality and player type. Some contextual information can help to know about this mood, like the hour and the day. For example, a user may expect a more relaxing activity after lunch. Furthermore, expert systems are limited as they are static. Another improvement we plan to do is the use of machine learning techniques to automatically adapt the adaptation rules themselves, based on the experience with the previous users.

\section{REFERENCES}

Andrade G., Ramalho G., Gomes A.S., Corruble V., 2006. Dynamic Game Balancing: an Evaluation of User Satisfaction, in: Proceedings of the 2nd Artificial Intelligence and Interactive Digital Entertainment Conference (AIIDE06), AAAI Press.

Bartle, R. 1996. Hearts, Clubs, Diamonds, Spades: Players Who Suit MUDs. Journal of MUD Research 1, 1.

Beck, J., 2005. Engagement tracing: using response times to model student disengagement. Artificial intelligence in education: Supporting learning through intelligent and socially informed technology 125,88 .

Bernardini, A., Conati, C., 2010. Discovering and recognizing student interaction patterns in exploratory learning environments, in: Intelligent Tutoring Systems. pp. 125-134.

Bouvier, P., Lavoué, E., Sehaba, K., George, S., 2013. Identifying Learner's Engagement in Learning Games: a Qualitative Approach based on Learner's Traces of Interaction, in: 5th International Conference on Computer Supported Education (CSEDU 2013), Aachen, Germany. pp. 6-8.Brusilovsky 2001

Charlier, N., Michela, O., Remmele, B., Whitton, N., 2012. Not Just for Children: Game-Based Learning for Older Adults, in: 6th European Conference on Games Based Learning, Cork, Ireland. pp. 102-108.

Cheng, T.I.C., n.d. Cheng, L.-T., Shami, S., Casey, D., Muller, M., DiMicco, J., Patterson, J., others, 2011. Finding moments of play at work, in: CHI 2011 Workshop (2-5). Vancouver: Canada.

Cocea, M., 2006. Assessment of motivation in online learning environments, in: Adaptive Hypermedia and Adaptive Web-Based Systems. pp. 414-418.

Conati, C., Manske, M., 2009. Evaluating adaptive feedback in an educational computer game, in: Intelligent Virtual Agents. pp. 146-158.

Deterding, S., Dixon, D., Khaled, R., Nacke, L., 2011. From game design elements to gamefulness: defining gamification, in: Proceedings of the 15th International Academic MindTrek Conference: Envisioning Future Media Environments. pp. 9-15.

Eglesz, D., Fekete, I., Kiss, O.E., Izso, L., 2005. Computer games are fun? On professional games and players' motivations. Educational Media International 42, 117 124 (in Hainey, T., Connolly, T., Stansfield, M., Boyle, E., 2011. The differences in motivations of online game players and offline game players: A combined analysis of three studies at higher education level. Computers \& Education 57, 2197-2211.)

Ferro, L.S., Walz, S.P., Greuter, S., 2013. Towards personalised, gamified systems: an investigation into game design, personality and player typologies, in: Proceedings of The 9th Australasian Conference on Interactive Entertainment: Matters of Life and Death. p. 7.

Gamification Co, 2013, A New Perspective on the Bartle Player Types for Gamification - GCo [WWW Document], n.d. URL http://www.gamification.co/2013/08/12/a-new- 
perspective-on-the-bartle-player-types-forgamification/ (accessed 10.1.13).

Giroux, S., Pachet, F., Paquette, G., Girard, J., 1995. Des systèmes conseillers épiphytes. Revue d'intelligence artificielle 9, 165-190.

Hocine, N., Gouaïche, A., Di Loreto, I., Abrouk, L., 2011. Techniques d'adaptation dans les jeux ludiques et sérieux. Revue d'intelligence artificielle 25, 253-280.

KhanAcademy, 2006. www.khanacademy.org

Kobsa, A., Koenemann, J., Pohl, W., 2001. Personalised hypermedia presentation techniques for improving online customer relationships. The Knowledge Engineering Review 16, 111.

Kotaku, 2012, They've Narrowed Gamers Down to Eight Fundamental Types. Which Are You? [WWW Document], n.d. URL http://kotaku.com/5938464/theyve-narrowed-gamersdown-to-eight-fundamental-types-which-are-you (accessed 10.1.13).

Lazzaro, N., 2004. Why we play games : Four Keys to More Emotion Without Story. Technical Report, XEO Desig inc.

Maciuszek, D., Ruddeck, G., Martens, A., 2010. Component-based development of educational games: The case of the user interface, in: Proceedings of the 4th European Conference on Games-based Learning (ECGBL 2010), Reading, UK. pp. 208-217.

Marne, B., Carron, T., Labat, J.-M., Marfisi-Schottman, I., 2013. MoPPLiq: A Model For Pedagogical Adaptation of Serious Game Scenarios, in: Advanced Learning Technologies (ICALT), 2013 IEEE 13th International Conference On. pp. 291-293.

Mattheiss, E., Kickmeier-Rust, M.D., Steiner, C.M., Albert, D., 2010. Approaches to detect discouraged learners: Assessment of motivation in educational computer games. Proceedings of eLearning Baltics (eLBa) 10 .

Mozilla, 2011. http://openbadges.org

Poel, M., Heylen, D., Nijholt, A., Trappl, R., 2004. Emotion based Agent Architectures for Tutoring Systems: The INES Architecture, in: Cybernetics and Systems 2004. Workshop on affective computational entities.

Prensky, M., 2001. Digital game-based learning. McGrawHill, New York.

Sanchez, E. (2011). A game in the classroom, what did the students learn?. ESERA 2011, Lyon, France.

Togelius, J., De Nardi, R., Lucas, S.M., 2007. Towards automatic personalised content creation for racing games, in: Computational Intelligence and Games, 2007. CIG 2007. IEEE Symposium On. pp. 252-259.

De Vicente, A., Pain, H., 2002. Informing the detection of the students' motivational state: an empirical study, in: Intelligent Tutoring Systems. pp. 933-943.

Yee, N., 2006. Motivations for play in online games. CyberPsychology \& Behavior 9, 772-775.

Zichermann, G., Cunningham, C., 2011. Gamification by Design: Implementing game mechanics in web and mobile apps. O'Reilly Media, Inc. 